\title{
BMJ Open In utero and early childhood exposure to secondhand smoke in Taiwan: a population-based birth cohort study
}

\author{
Kai-Wen Cheng, ${ }^{1}$ Wan-Lin Chiang, ${ }^{2}$ Tung-Liang Chiang ${ }^{2}$
}

To cite: Cheng K-W, Chiang W-L, Chiang T-L. In utero and early childhood exposure to secondhand smoke in Taiwan: a population-based birth cohort study. BMJ Open 2017;7:e014016. doi:10.1136/ bmjopen-2016-014016

- Prepublication history and additional material is available. To view please visit the journal online (http://dx.doi.org/10. 1136/bmjopen-2016-014016)

Received 26 August 2016 Revised 25 February 2017 Accepted 6 April 2017
CrossMark

${ }^{1}$ Institute for Health Research and Policy and Department of Economics, University of Illinois at Chicago, Chicago, Illinois, USA ${ }^{2}$ Institute of Health Policy and Management, College of Public Health, National Taiwan University, Taipei, Taiwan

Correspondence to Professor Tung-Liang Chiang; tlchiang@ntu.edu.tw

\begin{abstract}
Objectives This study provides secondhand smoke (SHS) exposure data in utero and after birth when children were at 18 months, 36 months and 66 months old, and it identifies risk factors for the early childhood SHS among 18-month-old infants living in smoker and non-smoker households.

Study design The data come from the Taiwan Birth Cohort Study, a longitudinal survey of a birth cohort born in 2005. This study used the survey wave when children were 18 months old $(n=18845)$ for statistical analysis of early childhood SHS exposure. Logistic regression was used to identify the risk factors of the SHS exposure. Results Approximately $62 \%$ of the 18 -month-old infants lived in a household with at least one smoker, with the father being the smoker in $84 \%$ of those households. Among these infants living in a smoker household, $70 \%$ were exposed to SHS and $36 \%$ were exposed to heavy SHS in utero, and the prevalence was approximately $66 \%$ and $17 \%$ after birth for SHS and heavy SHS, respectively. The number and the existence of smokers in the household, parents' smoking status, father's educational attainment and being a first-born baby are strong predictors of early childhood heavy SHS exposure. Conclusions Encouraging families to have a smoke-free home environment, empowering women to ensure their perspectives and rights are embedded into tobacco control efforts and educating families about the health risks from childhood SHS exposure, especially among people living in households with smokers, will protect non-smoking adults and children from SHS exposure.
\end{abstract}

\section{INTRODUCTION}

Secondhand smoke (SHS) puts non-smoking adults and children at higher risk of premature death, illness and other adverse effects. The health risk from SHS is especially substantial among children given that their lungs are still developing. Newborns exposed to SHS, either in utero or after birth, have higher risk of premature birth, low birth weight and sudden infant death syndrome and children exposed to SHS have higher risk of acute respiratory illness, middle ear infections, bronchi, reduced lung function and asthma development. $^{1-3}$
Strengths and limitations of this study

- A unique dataset, which randomly selected newborns from all live births in 2005, tracks secondhand smoke (SHS) exposure in utero and when the children were 18 months, 36 months and 66 months old.

- Sample size is large, over 19000 children for all waves.

- The response rate is high (>92\%) for all waves.

- Parents or primary caregivers may under-report infant's SHS due to lack of awareness or social desirability bias.

Globally, it is estimated that over $40 \%$ of men smoke tobacco, whereas only approximately $10 \%$ of women smoke, and this gender discrepancy in tobacco smoking exists especially in middle and lower income countries. ${ }^{4}$ Although worldwide smoking prevalence is low among women, women and children comprise the major population exposed to SHS with a global profile such that $35 \%$ of non-smoking women and $40 \%$ of children were exposed to SHS in $2004 .^{5}$

The home is a major setting for SHS exposure. Children, particularly children of preschool ages, are most likely to be exposed to SHS at home given that very young children spend most of their time in the home and smoking restrictions in the home are usually rare. ${ }^{6}$ The existence of smoking household members serves as a strong predictor for SHS exposure among children. ${ }^{7}$ Findings from the global Youth Tobacco Survey conducted by the WHO indicated that approximately $44 \%$ of youths worldwide are exposed to SHS at home, $47 \%$ of whom have at least one parent who smokes. ${ }^{9}$

Taiwan is similar to other developing countries in that men are the main subgroup of smokers, whereas the smoking rate for women is very low $(40.0 \%$ for men, $4.8 \%$ for women in 2005 , decreasing to $33.5 \%$ for men and $4.4 \%$ for women in 2011). ${ }^{10}$ The 
prevalence of SHS exposure among non-smoking women and children is substantial given the high male smoking rate and the limited restrictions of smoking in homes and some public places; consequently, the risk of adverse health associated with SHS for women and children who live with smokers is particularly high. ${ }^{11-14}$ Previous studies using cross-sectional survey data in Taiwan indicated that over $60 \%$ of smoking parents with school-aged children smoke in the presence of their children, ${ }^{12}$ and approximately $45 \%$ of junior and senior high school students have been exposed to SHS at home..$^{10}$

However, few studies have investigated SHS exposure among children under 5 years old, the subgroup with developing lung systems that are most susceptible to SHS. These young children spend most of their time at home and are more likely to be exposed to SHS through their smoking household members than are older children.

This study uses birth cohort data, a longitudinal survey of a birth cohort born in 2005, and provides the prevalence of SHS exposure in utero and in children aged 18, 36 and 66 months. This study identifies risk factors of heavy SHS exposure among 18-month infants, aiming to explore potential sociodemographic disparities associated with the early childhood SHS exposure.

\section{METHODS}

\section{Data}

Data come from the Taiwan Birth Cohort Study (TBCS), a longitudinal survey of a nationally representative birth cohort born in 2005 in Taiwan. The TBCS used a two-stage stratified random sampling design and drew the study sample from the population-based birth database (National Birth Report Database) with an 11.7\% sampling rate, resulting in a nationally representative cohort of 24200 newborn individuals born in 2005 . Among those eligible newborns, 21248 infants completed a baseline survey at 6 months of age with a response rate of $87.8 \%$. These infants were subsequently recruited as cohort members. Three waves of follow-up surveys were conducted when the infants and young children were at 18 months, 36 months and 66 months of age, with response rates of $94.9 \%, 93.7 \%$ and $92.8 \%$, respectively. The TBCS is sponsored by Taiwan Health Promotion Administration designed to document the health and developmental trajectories of children in Taiwan, and the survey has been widely used in studies investigating topics in child development and health. ${ }^{15-17}$ Detailed information about the TBCS can be found in previous publications. $^{18-20}$

The survey was conducted via face-to-face interviews using standardised questionnaires with either the mother or a primary caregiver by trained interviewers, providing the information about children's health and development, child care, lifestyle and social and physical environment exposures. According to the 18-month survey, $98 \%$ of the respondents are mothers, $1.23 \%$ are primary caregivers and $0.76 \%$ are both mothers and primary caregivers. Among the primary caregivers, the majority of them $(90 \%)$ are fathers or grandparents. The TBCS survey protocol and questionnaires have been reviewed and approved by the Institutional Review Board (IRB) of the Bureau of Health Promotion, Department of Health and the Directorate-General of Budget, Accounting, and Statistics, Executive Yuan, Republic of China (No 94-C3-0940005257). This study is approved by the IRB at National Taiwan University Hospital (ID number: 201503081RINB). The survey, the wave when children were 18 months, is attached as a supplementary file (see online supplementary file).

This study uses four waves of the TBCS, when the infants and young children were 6 months, 18 months, 36 months and 66 months old, to provide a time trend of SHS exposure across four time periods (in utero, 18 months, 36 months and 66 months).

The 6-month wave provided retrospective information regarding women's SHS exposure during their pregnancy. The 18-month, 36-month and 66-month waves provided information regarding young children's current SHS exposure. However, the 6-month wave did not provide information on children's current SHS exposure. The sample sizes are 21 248, 20 172, 19910 and 19721 for the 6-month, 18-month, 36-month and 66-month waves, respectively.

This study restricts the study sample to the respondents who consistently answered 6-month, 18-month, 36-month and 66-month survey waves, and that leads in the sample size equalling 18845. Furthermore, this study uses the 18-month wave, the first wave of the TBCS, including children's current SHS information conducted between 2006 and 2007 for bivariate and multivariate analyses of early childhood SHS exposure.

The in utero SHS is retrospectively reported in the 6-month wave and coded as ' 1 ' ' if the mother answered '1-2 days per week', ' $3-5$ days per week' or 'almost every day' to the question "During your pregnancy, did anyone smoke anywhere in front of you?" and ' 0 ' if the mother answered 'never'. The in utero heavy SHS is coded as ' 1 ' if the mother answered either 'almost every day' or ' $3-5$ days per week' to that question and ' 0 ' if the mother answered '1-2 days per week', 'less than 1 day per week' or 'never'. The childhood SHS is measured separately in the 18-month, 36-month and 66-month waves and coded as ' 1 ' if the mother or primary caregiver answered 'occasionally', 'often' or 'every day' to the question "How often is your baby exposed to secondhand smoke?" and ' 0 ' if the mother answered 'never'. The heavy childhood SHS is coded as ' 1 ' either 'every day' or 'often' to that question and ' 0 ' either 'never' or 'occasionally'.

Parent's smoking status was ' 1 ' if one answered 'yes' to the question "Did you smoke during the past month?" and ' 0 ' otherwise. If a smoker smoked over 20 cigarettes a day, he or she was defined as a heavy smoker, otherwise not a heavy smoker. Smoker household was coded ' 1 ' if any parent or other household members smoked and ' 0 'if none of them smoked. 
All control variables of the statistical analysis, including characteristics of the parents, children and household, were measured when the child was 18 months except for the parents' age at the birth of child (answered at 6 months).

\section{Statistical methods}

\section{Descriptive analysis}

The sample was classified into two groups: young children living in a smoker household and those living in a non-smoker household. The crude proportion of the in utero and heavy childhood SHS exposure, when they were 18 months, 36 months and 66 months old, was provided for all children, those in smoker and non-smoker households alike.

Summary statistics for outcome (heavy early childhood SHS exposure) and covariates (parents' characteristics, child's characteristics and household characteristics) are provided for the 18-month-old infants in both smoker and non-smoker households.

Bivariate associations of each covariate with heavy and non-heavy early childhood SHS exposure were tested with $\chi^{2}$ tests for categorical variables and analysis of variance for continuous variables.

\section{Statistical analysis}

This study used logistic regression to estimate the odds of heavy early childhood SHS exposure for two groups (infants living in a smoker household and infants living in a non-smoker household), separately. This approach identifies the risk factors associated with heavy early childhood SHS exposure, and it captures potential differences in the associations between heavy early childhood SHS exposure and covariates among infants living in smoker and non-smoker households.

All statistical analyses were conducted by SAS version 9.3.

\section{RESULTS}

\section{Trends of childhood SHS exposure}

In general, the proportion of young children who were exposed to heavy SHS was $26.1 \%$ in utero, and it declined significantly after birth to $11.6 \%, 12.1 \%$ and $9.5 \%$ when the children were 18 months, 36 months and 66 months old, respectively (figure 1).

When the sample was divided into those who live in smoker versus non-smoker households, the trend presents similar patterns between the two subsamples (the heavy SHS prevalence declined significantly after birth). The percentage of young children exposed to heavy SHS is consistently high for those living in smoker households.

\section{Baseline summary statistics}

Among the 18-month-old infants, $61.8 \%$ lived in a smoker household and $37.8 \%$ lived in a non-smoker household. The average age was 36.5 years for fathers and 29.9 years for mothers. Educational attainment was

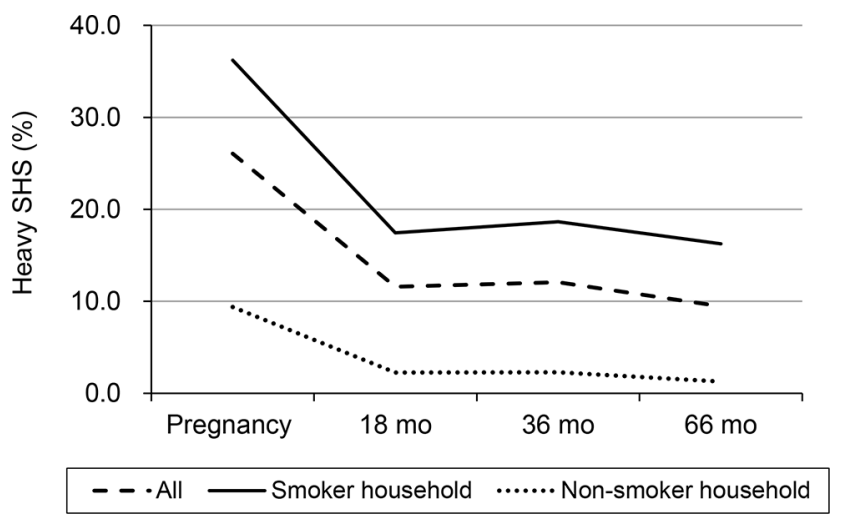

Figure 1 Prevalence of early childhood secondhand smoke (SHS) exposure in utero and after birth in smoker and nonsmoker households. The proportion of young children who were exposed to heavy SHS declined significantly after birth. The percentage of children exposed to heavy SHS is consistently higher for those living in smoker households than for those living in non-smoker households.

higher for parents living in non-smoker households than for those living in smoker households. Approximately half of the infants (47\%) had the father as the only smoker in the household, $0.5 \%$ had the mother as the only smoker, $4.9 \%$ had both parents as smokers and $46.5 \%$ had neither parent as a smoker. Similarly, among infants living in smoker households, $76 \%$ had the father as the only smoker, $7.9 \%$ had the mother as the only smoker and $14 \%$ had other family member as the only smoker. On average, smoking fathers smoked approximately 15 cigarettes per day and smoking mothers smoked approximately 9 cigarettes per day (table 1 ).

Among the 18-month-old infants, 52\% were boys and $50 \%$ were first-born children. On average, $55.2 \%$ of the 18-month-old infants were exposed to SHS, with $66 \%$ exposed to SHS in a smoker household and $37.7 \%$ exposed to SHS in a non-smoker household. A total of $11.6 \%$ of the infants were exposed to heavy SHS, with $17.3 \%$ exposed to heavy SHS from living in a smoker household and $2.3 \%$ exposed from living in a non-smoker household. On average, family income for infants living in non-smoker households $(<30000$ : $6.3 \%, 30000-100000: 74.6 \%,>100000: 18.9 \%)$ was higher than that for smoker households $(<30000$ : 14.6\%, 30000-100000: 77.2\%, >100000: 7.7\%). The average number of smokers living in a smoker household with infants was 1.4.

\section{Bivariate analysis}

Results from bivariate analyses (table 2) indicate that presence of heavy SHS is significantly associated with parents' younger age, lower education level, not employed, currently smoking and higher smoking intensity (all $\mathrm{p}<0.01)$. Heavy SHS was significantly higher among non-first-born children than first-born children $(\mathrm{p}<0.01)$.

Household characteristics such as lower family income, smoking parents and more smokers in the household 
Open Access

Table 1 Baseline summary descriptive data (measured when the children were 18 months old), $n$ ( $\%$ or mean $\pm S D$ )

\begin{tabular}{|c|c|c|c|}
\hline \multirow[b]{2}{*}{ Variables } & \multicolumn{3}{|l|}{ No of observations } \\
\hline & All households & Non-smoker households & Smoker households \\
\hline Total & $18845(100.0)$ & $7130(100.0)$ & $11651(100.0)$ \\
\hline \multicolumn{4}{|l|}{ Parent's characteristics } \\
\hline Father's age (years) & $18845(36.5 \pm 13.8)$ & $7130(35.7 \pm 9.1)$ & $11651(36.9 \pm 15.6)$ \\
\hline$<25$ & $475(2.5)$ & $53(0.7)$ & 419 (3.6) \\
\hline $25-29$ & 3440 (18.3) & $858(12.0)$ & $2574(22.1)$ \\
\hline $30-34$ & $6592(35.0)$ & 2729 (38.3) & 3859 (33.1) \\
\hline$\geq 35$ & 8338 (44.2) & $3490(49.0)$ & $4799(41.2)$ \\
\hline Mother's age (years) & $18845(29.9 \pm 4.8)$ & $7130(31.4 \pm 4.3)$ & $11651(28.9 \pm 4.9)$ \\
\hline$<25$ & 2707 (14.4) & $409(5.7)$ & $2283(19.6)$ \\
\hline $25-29$ & $6117(32.4)$ & $1848(25.9)$ & $4251(36.5)$ \\
\hline $30-34$ & $6760(35.9)$ & $3236(45.4)$ & $3510(30.1)$ \\
\hline$\geq 35$ & 3261 (17.3) & $1637(23.0)$ & 1607 (13.8) \\
\hline \multicolumn{4}{|l|}{ Father's education level } \\
\hline Junior high or below & 2500 (13.3) & $409(5.7)$ & 2079 (17.8) \\
\hline Senior high & 7454 (39.6) & $1772(24.9)$ & $5664(48.6)$ \\
\hline Junior college & $4134(21.9)$ & $1790(25.1)$ & $2332(20.0)$ \\
\hline College and above & $4623(24.5)$ & $3140(44.0)$ & $1479(12.7)$ \\
\hline Missing & $134(0.7)$ & $19(0.3)$ & $97(0.8)$ \\
\hline \multicolumn{4}{|l|}{ Mother's education level } \\
\hline Junior high or below & 2637 (14.0) & $521(7.3)$ & $2103(18.1)$ \\
\hline Senior high & 7526 (39.9) & $1927(27.0)$ & $5571(47.8)$ \\
\hline Junior college & $4797(25.5)$ & $2147(30.1)$ & $2638(22.6)$ \\
\hline College and above & $3852(20.4)$ & $2527(35.5)$ & $1314(11.3)$ \\
\hline Missing & $33(0.2)$ & $8(0.1)$ & $25(0.2)$ \\
\hline \multicolumn{4}{|l|}{ Parents' employment status } \\
\hline Father employed & $18053(95.8)$ & $6969(97.7)$ & $11075(95.1)$ \\
\hline Missing & $182(1.0)$ & $9(0.1)$ & $121(0.6)$ \\
\hline Mother employed & $11475(60.9)$ & $4698(65.9)$ & $6733(57.8)$ \\
\hline Missing & $108(0.6)$ & $9(0.1)$ & $92(0.5)$ \\
\hline \multicolumn{4}{|l|}{ Parents' smoking status } \\
\hline Only father smokes & $8854(47.0)$ & $0(0.0)$ & $8854(76.0)$ \\
\hline Only mother smokes & $87(0.4)$ & $0(0.0)$ & $87(0.7)$ \\
\hline Both parents smoke & $923(4.9)$ & $0(0.0)$ & $923(7.9)$ \\
\hline None of them smoke & $8760(46.5)$ & $7130(100.0)$ & $1630(14.0)$ \\
\hline Missing & $221(1.2)$ & $0(0.0)$ & $157(1.4)$ \\
\hline \multicolumn{4}{|c|}{ Parents' smoking intensity (smokers) } \\
\hline Father's cigarettes per day & $9782(15.2 \pm 9.5)$ & $0(-)$ & $9782(15.2 \pm 9.4)$ \\
\hline $\begin{array}{l}\text { Mother's cigarettes per } \\
\text { day }\end{array}$ & $1052(9.3 \pm 6.8)$ & $0(-)$ & $1052(9.3 \pm 6.8)$ \\
\hline \multicolumn{4}{|l|}{ Children's characteristics } \\
\hline Child being a boy & $9912(52.6)$ & 3765 (52.8) & $6114(52.5)$ \\
\hline \multicolumn{4}{|l|}{ First-born child } \\
\hline Yes & 9468 (50.2) & 3579 (50.2) & 5845 (50.2) \\
\hline No & 9367 (49.7) & 3551 (49.8) & $5796(49.7)$ \\
\hline
\end{tabular}


Table 1 Continued

\begin{tabular}{|c|c|c|c|}
\hline \multirow[b]{2}{*}{ Variables } & \multicolumn{3}{|l|}{ No of observations } \\
\hline & All households & Non-smoker households & Smoker households \\
\hline Missing & $10(0.1)$ & $0(0.0)$ & $10(0.1)$ \\
\hline \multicolumn{4}{|l|}{ Children's SHS exposure } \\
\hline \multicolumn{4}{|l|}{ General SHS exposure } \\
\hline Never & $8441(44.8)$ & 4439 (62.3) & 3961 (34.0) \\
\hline Ever & $10401(55.2)$ & $2691(37.7)$ & $7690(66.0)$ \\
\hline Missing & $3(0.0)$ & $0(0.0)$ & $0(0.0)$ \\
\hline \multicolumn{4}{|l|}{ SHS intensity* } \\
\hline $\begin{array}{l}\text { Non-heavy SHS } \\
\text { exposure }\end{array}$ & $16659(88.4)$ & $6968(97.7)$ & $9632(82.7)$ \\
\hline Heavy SHS exposure & $2183(11.6)$ & $162(2.3)$ & 2019 (17.3) \\
\hline Missing & $3(0.0)$ & $0(0.0)$ & $0(0.0)$ \\
\hline \multicolumn{4}{|l|}{ Household characteristics } \\
\hline \multicolumn{4}{|l|}{ Family income (NTD) } \\
\hline$<30000$ & 2195 (11.6) & $449(6.3)$ & 1705 (14.6) \\
\hline $30000-100000$ & $14332(76.1)$ & 5319 (74.6) & 8996 (77.2) \\
\hline$>100000$ & 2249 (11.9) & 1348 (18.9) & $900(7.7)$ \\
\hline Missing & $69(0.4)$ & $14(0.2)$ & $50(0.4)$ \\
\hline No of smokers in the family & $18821(0.9 \pm 1.0)$ & $7130(0.0 \pm 0.0)$ & $11628(1.4 \pm 0.9)$ \\
\hline
\end{tabular}

40 New Taiwan Dollars (NTD) $£ 1 ; 30$ NTD $\fallingdotseq 1$ US\$.

*Heavy SHS: mother reported 'often' or 'every day' to the question "How often is your baby exposed to secondhand smoke?"; non-heavy SHS: 'never' or 'occasionally' to that question.

SHS, secondhand smoke.

were found to be significantly associated with heavy SHS exposure (all $\mathrm{p}<0.01)$.

\section{Multivariate analysis}

The results from multivariate logistic regression (table 3) indicate that among all of the 18-month-old infants, the presence of a smoker in the household increased the likelihood for them to be exposed to heavy SHS. The more smokers present in the household, the more likely they are to be exposed to heavy SHS. The older the mother is, the less likely child is to be exposed to heavy SHS. The higher the father and mother's educational status is, the less likely the child is to be exposed to heavy SHS. Being a first-born child is associated with decreased likelihood of heavy SHS exposure.

After dividing the infants into those living in smoker versus non-smoker households, parental characteristics such as age of mother and education of father and mother are significantly associated with the heavy early childhood SHS exposure for those living in smoker households but not among those living in non-smoker households. We found that among children living in smoker households, the older their mother is and the higher their father or mother's education is, the less likely the child is to be exposed to heavy SHS. Among infants living in a smoker household, the subgroup of infants having both smoker parents have significant higher likelihood to be exposed to heavy SHS compared with their counterparts. The mother's employment status was found to be significantly associated with increased SHS exposure for infants in a smoker household but decreased SHS exposure for infants in non-smoker households. Being a first-born child was found to be associated with decreased likelihood of SHS exposure for infants living in either a non-smoker or smoker household.

\section{DISCUSSION}

To our knowledge, this is the first study using a birth cohort data and investigating SHS exposure in utero and among young children at different ages under 5 years old. This study uses a unique dataset, the TBCS data, which randomly selected newborns from among all live births in 2005, and tracks SHS exposure in utero and when the children were 18 months, 36 months and 66 months old.

Our results indicate that among the 18-month-old infants, $61.8 \%$ of them lived in a household with at least one smoker, with the father being the smoker in $84 \%$ of those households. This result confirms previous studies in East Asia indicating that most childhood SHS may come from the father and other household members, whereas $76 \%$ of infants living in a smoker 
Table 2 Early childhood SHS exposure by household, parental and children's characteristics, n (\%)

\begin{tabular}{llccc} 
Characteristics & Total $(\mathbf{n})$ & Non-heavy SHS & Heavy SHS & p Value \\
\hline Total & 18845 & $16659(88.4)$ & $2183(11.6)$ &
\end{tabular}

Parent's characteristics

\begin{tabular}{|c|c|c|c|c|}
\hline Father's age (years) & & & & $<0.0001$ \\
\hline$<25$ & 475 & $373(78.5)$ & $102(21.5)$ & \\
\hline $25-29$ & 3440 & $2939(85.4)$ & $501(14.6)$ & \\
\hline $30-34$ & 6592 & 5909 (89.6) & $683(10.4)$ & \\
\hline$\geq 35$ & 8338 & 7438 (89.2) & $897(10.8)$ & \\
\hline Mother's age (years) & & & & $<0.0001$ \\
\hline$<25$ & 2707 & $2171(80.2)$ & $535(19.8)$ & \\
\hline $25-29$ & 6117 & 5281 (86.3) & $835(13.7)$ & \\
\hline $30-34$ & 6760 & $6195(91.6)$ & $564(8.3)$ & \\
\hline$\geq 35$ & 3261 & $3012(92.4)$ & $249(7.6)$ & \\
\hline Father's education level & & & & $<0.0001$ \\
\hline Junior high or below & 2500 & $1934(77.4)$ & $564(22.6)$ & \\
\hline Senior high & 7454 & $6337(85.0)$ & $1117(15.0)$ & \\
\hline Junior college & 4134 & 3808 (92.1) & $325(7.9)$ & \\
\hline College and above & 4623 & $4469(96.7)$ & 154 (3.3) & \\
\hline Mother's education level & & & & $<0.0001$ \\
\hline Junior high or below & 2637 & $2076(78.7)$ & $559(21.2)$ & \\
\hline Senior high & 7526 & $6442(85.6)$ & $1083(14.4)$ & \\
\hline Junior college & 4797 & $4422(92.2)$ & $375(7.8)$ & \\
\hline College and above & 3852 & 3689 (95.8) & $163(4.2)$ & \\
\hline \multicolumn{5}{|c|}{ Parents' employment status } \\
\hline Father employed & 18053 & $16007(88.7)$ & $2045(11.3)$ & $<0.0001$ \\
\hline Father not employed & 610 & $503(82.5)$ & $107(17.5)$ & \\
\hline Mother employed & 11475 & 10337 (90.1) & $1137(9.9)$ & $<0.0001$ \\
\hline Mother not employed & 7262 & $6240(85.9)$ & $1022(14.1)$ & \\
\hline Parents' smoking status & & & & $<0.0001$ \\
\hline Only father smokes & 8854 & $7404(83.6)$ & $1450(16.4)$ & \\
\hline Only mother smokes & 87 & 75 (86.2) & $12(13.8)$ & \\
\hline Both parents smoke & 923 & $638(69.1)$ & $285(30.9)$ & \\
\hline None of them smoke & 8760 & $8364(95.5)$ & $396(4.5)$ & \\
\hline \multicolumn{5}{|l|}{ Heavy smoker } \\
\hline Father & 4506 & $3351(74.4)$ & $1155(25.6)$ & $<0.0001$ \\
\hline Mother & 162 & $80(49.4)$ & $82(50.6)$ & $<0.0001$ \\
\hline \multicolumn{5}{|l|}{ Children's characteristics } \\
\hline Gender & & & & 0.189 \\
\hline Boy & 9912 & $8733(88.1)$ & $1177(11.9)$ & \\
\hline Girl & 8932 & $7926(88.7)$ & $1006(11.3)$ & \\
\hline Birth order & & & & $<0.0001$ \\
\hline First-born child & 9468 & $8491(89.7)$ & $976(10.3)$ & \\
\hline Non-first-born child & 9365 & $8158(87.1)$ & $1207(12.9)$ & \\
\hline \multicolumn{5}{|l|}{ Household characteristics } \\
\hline Family income (NTD) & & & & $<0.0001$ \\
\hline$<30000$ & 2195 & $1781(81.1)$ & $414(18.9)$ & \\
\hline
\end{tabular}




\begin{tabular}{|c|c|c|c|c|}
\hline Characteristics & Total (n) & Non-heavy SHS & Heavy SHS & p Value \\
\hline $30000-100000$ & 14332 & $12694(88.6)$ & $1637(11.4)$ & \\
\hline Any smoker present in the household & & & & $<0.0001$ \\
\hline No & 7130 & 6968 (97.7) & $162(2.3)$ & \\
\hline No of smokers in the family & & & & $<0.0001$ \\
\hline 0 & 7790 & 7472 (95.9) & $316(4.1)$ & \\
\hline 1 & 7309 & $6463(88.4)$ & $846(11.6)$ & \\
\hline 2 & 2513 & $1927(76.7)$ & $586(23.3)$ & \\
\hline
\end{tabular}

40 New Taiwan Dollars (NTD) $\fallingdotseq £ 1 ; 30$ NTD $\fallingdotseq 1$ US\$.

SHS, secondhand smoke.

household have father being the only smoker, and $14 \%$ have other family member and $0.7 \%$ have mother being the only smoker. ${ }^{721}$ These results indicate the urgent need to keep homes smoke-free to protect children from SHS exposure. Indeed, banning smoking in the home is found to be associated with a significant reduction in urinary cotinine to creatinine ratio in infants. ${ }^{22-25}$ However, smoking restrictions in homes are not mandated by legal regulations, and the voluntary restriction of smoking is usually rare. Efforts are needed to encourage Taiwanese families to adopt their own policy of restricting smoking in the home setting.

Taiwan is similar to many other Asian countries in that the familial values are deeply influenced by Confucianism, with an expectation of respecting the elderly and males to maintain the patriarchal family. This philosophy of Confucianism and patriarchy embedded in Chinese familial values may cause married women and children to be hesitant to change the smoking behaviour of their male household members or to ask male smokers to smoke outside of the home. ${ }^{26} 27$ Therefore, in addition to providing women with advice and information about the harms of SHS exposure, their husbands, partners and other household members should be informed with the risks of such exposure on pregnant women as well as children. Most importantly, smoking cessation support should be provided to increase the quit rates, which ultimately would reduce SHS exposure. ${ }^{28}$

Previous studies have indicated that smoke-free legislation in public places can spill over to the home setting through creating a norm of not smoking around non-smokers. ${ }^{16}{ }^{29-32}$ Indeed, a few studies found that the comprehensive smoke-free laws enacted in 2009 in Taiwan reduced adult non-smokers' SHS exposure in the home and even increased smoking cessation. ${ }^{11} 14$ The enforcement of smoke-free environments in many public places may further reduce women and children's SHS exposure at home. In our study, we found that the
SHS exposure declined significantly from $12.1 \%$ when the children were 36 months old in 2008 to $9.5 \%$ when the children were 66 months old in 2010-2011. The decreasing patterns were similar when the sample was divided into those who live in smoker versus non-smoker households. Part of the decrease may result from the implementation of comprehensive smoke-free laws in 2009. Future studies may use the TBCS data to investigate the effect of comprehensive smoke-free laws on children's SHS exposure by comparing the exposure between precomprehensive and postcomprehensive smoke-free laws, controlling for environmental factors and household characteristics.

Our results indicated that the first-born children are significantly less likely to be exposed to heavy SHS than later-born children are. This finding confirms previous studies indicating that first-born children tend to receive higher quality care in social, affectionate and caretaking activities during early childhood than later borns do. ${ }^{33-35}$ In addition, the finding of the high in utero SHS exposure indicates a serious lack of knowledge on and social protection from the harms of SHS exposure during pregnancy, leading pregnant women continually being exposed to SHS. ${ }^{36-38}$

Our results indicated that several factors are significantly associated with heavy early childhood SHS exposure, which allows the specific groups to be targeted by interventions to be identified, for example households with smokers, households with more than one smoker, both parents smoke, parents with lower educational attainment, mothers of younger age and non-first-born children. More educational interventions and resources need to be aimed at these target groups to reduce early childhood SHS exposure from their household smokers through education about the health risks from SHS exposure.

A potential limitation this study has is that parents or primary caregivers may under-report infant's SHS due to lack of awareness or social desirability bias. 
Table 3 Risk factors for heavy SHS exposure for children in all, smoker and non-smoker households

\begin{tabular}{llll} 
Characteristics & All households & Non-smoker \\
\hline
\end{tabular}

Total

Parent's characteristics

Father's age (years) (ref: <25)

\begin{tabular}{|c|c|c|c|}
\hline $25-29$ & $0.82(0.63-1.07)$ & $0.81(0.62-1.06)$ & $1.54(0.19-12.45)$ \\
\hline 30-34 & $0.86(0.66-1.13)$ & $0.85(0.65-1.12)$ & $1.46(0.18-11.86)$ \\
\hline$\geq 35$ & $0.87(0.66-1.14)$ & $0.88(0.67-1.16)$ & $1.24(0.15-10.15)$ \\
\hline $25-29$ & $0.96(0.84-1.11)$ & $0.98(0.85-1.13)$ & $0.99(0.46-2.13)$ \\
\hline 30-34 & $0.84(0.71-0.99)^{*}$ & $0.84(0.71-1.00)^{\star}$ & $0.93(0.41-2.09)$ \\
\hline \multicolumn{4}{|c|}{ Father's education level (ref: sjunior high) } \\
\hline Senior high & $0.77(0.67-0.87)^{\star \star \star}$ & $0.75(0.66-0.85)^{\star \star \star}$ & $2.04(0.85-4.89)$ \\
\hline Junior college & $0.58(0.48-0.69)^{\star \star \star}$ & $0.56(0.47-0.67)^{\star \star \star}$ & $1.35(0.54-3.41)$ \\
\hline College and above & $0.37(0.29-0.48)^{\star \star *}$ & $0.33(0.25-0.43)^{\star \star *}$ & $1.10(0.42-2.86)$ \\
\hline \multicolumn{4}{|c|}{ Mother's education level (ref: sjunior high) } \\
\hline College and above & $0.80(0.62-1.02)$ & $0.84(0.65-1.10)$ & $0.83(0.35-1.99)$ \\
\hline \multicolumn{4}{|l|}{ Parents' employment status } \\
\hline Father employed (ref: yes) & $1.00(0.78-1.29)$ & $0.99(0.76-1.29)$ & $1.21(0.42-3.49)$ \\
\hline Mother employed (ref: yes) & $1.10(0.99-1.21)$ & $1.18(1.06-1.32)^{\star \star}$ & $0.46(0.31-0.68)^{\star \star \star}$ \\
\hline
\end{tabular}

Parents' smoking status (ref: none of them smoke)

\begin{tabular}{|c|c|c|c|}
\hline Only father smoke & & $0.87(0.74-1.01)$ & \\
\hline Only mother smoke & & $0.63(0.32-1.22)$ & \\
\hline Both parents smoke & & $1.62(1.30-2.00)^{\star \star \star}$ & \\
\hline \multicolumn{4}{|l|}{ Children's characteristics } \\
\hline Child being a boy (Ref: girl) & $1.07(0.97-1.18)$ & $1.07(0.96-1.18)$ & $1.04(0.76-1.43)$ \\
\hline First-born child (Ref: no) & $0.73(0.66-0.81)^{\star \star \star}$ & $0.74(0.67-0.83)^{\star \star \star}$ & $0.62(0.44-0.87)^{\star \star}$ \\
\hline \multicolumn{4}{|l|}{ Family income (NTD) (ref: <30000) } \\
\hline $30000-100000$ & $0.97(0.83-1.12)$ & $0.98(0.84-1.13)$ & $0.88(0.43-1.82)$ \\
\hline$>100000$ & $0.88(0.68-1.13)$ & $0.88(0.67-1.16)$ & $0.77(0.32-1.82)$ \\
\hline Any smoker present in the household (ref: no) & $3.79(3.03-4.73)^{\star * *}$ & & \\
\hline No of smokers in the family & $1.45(1.38-1.53)^{\star \star \star}$ & $1.45(1.38-1.53)^{\star \star \star}$ & \\
\hline
\end{tabular}

${ }^{*} \mathrm{p}<0.05 ;{ }^{* *} \mathrm{p}<0.01 ;{ }^{* * *} \mathrm{p}<0.001$.

40 New Taiwan Dollars (NTD) $\fallingdotseq £ 1 ; 30$ NTD $\fallingdotseq 1$ US\$.

SHS, secondhand smoke.

Nevertheless, in our sample, $55.2 \%$ of primary caregivers indicated that their children were exposed to SHS, and this prevalence is higher than previously found in Taiwan. ${ }^{10} 13$ Another concern regarding systematic bias in childhood SHS exposure may arise if under-reporting occurs in a certain demographic or socioeconomic subgroup and not others. However, a study using multiple SHS exposure measures, both self-reporting and serum cotinine level, indicated that exposure patterns by demographic characteristics were similar among those two measures. ${ }^{39}$

\section{CONCLUSIONS}

This study investigated the early childhood SHS exposure among 18-month-old infants, a subgroup of young children spending most of their time at home and most likely to be exposed to household SHS through 
their household members. The results indicate that most early childhood SHS comes from the father and other household members, whereas the smoking rate for women in this study setting is very low. Encouraging families to maintain a smoke-free home environment, empowering women to ensure their perspectives and rights are embedded into tobacco control efforts, and educating families about the health risks from childhood SHS exposure, especially among children living in households with smokers, will protect non-smoking women and their children from SHS exposure.

Acknowledgements At the time of writing, K-WC was with the Institute of Health Policy and Management at National Taiwan University. The authors gratefully acknowledge the time and continuing support from the participating families of the Taiwan Birth Cohort Study.

Contributors K-WC: Conceived the topic, designed the statistical plans and drafted the article. W-LC: Did the actual statistical run and conducted the editing during the manuscript preparation. T-LC: Initiated the collaborative project, provided critical comments and revised the draft article. All authors approved the final manuscript as submitted and agree to be accountable for all aspects of the work.

Funding The study was funded by the Health Promotion Administration, Ministry of Health and Welfare (DOH94-HP-1802, DOH95-HP-1802, DOH96-HP-1702 and DOH99-HP-1702)

Competing interests T-LC is the principle investigator of the Taiwan Birth Cohort Study.

Ethics approval Institutional Review Board at National Taiwan University Hospital. Provenance and peer review Not commissioned; externally peer reviewed.

Data sharing statement № additional data available.

Open Access This is an Open Access article distributed in accordance with the Creative Commons Attribution Non Commercial (CC BY-NC 4.0) license, which permits others to distribute, remix, adapt, build upon this work non-commercially, and license their derivative works on different terms, provided the original work is properly cited and the use is non-commercial. See: http://creativecommons.org/ licenses/by-nc/4.0/

(C) Article author(s) (or their employer(s) unless otherwise stated in the text of the article) 2017. All rights reserved. No commercial use is permitted unless otherwise expressly granted.

\section{REFERENCES}

1. Landrigan P, DiLiberti J, Graef J, et al. Involuntary smoking-a hazard to children. Pediatrics 1986;77:755-7.

2. Mannino DM, Siegel M, Husten C, et al. Environmental tobacco smoke exposure and health effects in children: results from the 1991 National Health Interview Survey. Tob Control 1996;5:13-18.

3. Samet JM, Lewit EM, Warner KE. Involuntary smoking and children's health. Future Child 1994;4:94-114.

4. WHO. WHO Report on the global tobacco epidemic, 2008: the MPOWER package. Geneva: WHO, 2008.

5. Oberg M, Jaakkola MS, Woodward A, et al. Worldwide burden of disease from exposure to second-hand smoke: a retrospective analysis of data from 192 countries. Lancet 2011;377:139-46.

6. Ashley MJ, Ferrence R. Reducing children's exposure to environmental tobacco smoke in homes: issues and strategies. Tob Control 1998;7:61-5.

7. Leung GM, Ho LM, Lam TH. Secondhand smoke exposure, smoking hygiene, and hospitalization in the first 18 months of life. Arch Pediatr Adolesc Med 2004;158:687-93.

8. Wipfli H, Avila-Tang E, Navas-Acien A, et al. Secondhand smoke exposure among women and children: evidence from 31 countries. Am J Public Health 2008;98:672-9.

9. GTSS Collaborative Group. A cross country comparison of exposure to secondhand smoke among youth. Tob Control 2006;15(Suppl 2):ii4.

10. Health Promotion Administration MoHaW. Taiwan tobacco control annual report 2012. Taiwan: Ministry of Health and Welfare, 2012.
11. Chang FC, Sung HY, Zhu SH, et al. Impact of the 2009 Taiwan tobacco hazards prevention act on smoking cessation. Addiction 2014;109:140-6.

12. Liao YM, Chen YT, Kuo LC, et al. Factors associated with parental smoking in the presence of school-aged children: a cross-sectional study. BMC Public Health 2013;13:819.

13. Lin PL, Huang HL, Lu KY, et al. Second-hand smoke exposure and the factors associated with avoidance behavior among the mothers of pre-school children: a school-based cross-sectional study. BMC Public Health 2010;10:606.

14. Tsai YW, Chang LC, Sung HY, et al. The impact of smokefree legislation on reducing exposure to secondhand smoke: differences across gender and socioeconomic groups. Tob Control 2015;24:62-9.

15. Wu JCL, Chiang TL. Differential susceptibility to effects of the home environment on motor developmental outcomes of preschool children: low birthweight status as a susceptibility factor. Early Child Dev Care 2016;186:1227-42.

16. Wu WC, Wu JCL, Chiang TL. Variation in the association between socioeconomic status and breastfeeding practices by immigration status in Taiwan: a population based birth cohort study. BMC Pregnancy Childbirth 2015;15:298.

17. Lin YC, Wu JCL, Chiou ST, et al. Healthy living practices in families and child health in Taiwan. Int $J$ Public Health 2015;60:691-8.

18. Chiang TL, Lin SJ, Chang MJ. An introduction to Taiwan Birth Cohort Study: background, design, and characteristics of participated children. In: Chiang TL, Lin SJ, eds. The health profiles of taiwanese children in the 21st century: from birth to thirty-six months [in Chinese]. Taipei: Health Promotion Administration, Ministry of Health and Welfare, 2010:1-12.

19. Health Promotion Administration, Ministry of Health and Welfare. Taiwan Birth Cohort Study (TBCS). http://www.hpa.gov.tw/ EngPages/List.aspx?nodeid=1077 (accessed 24 Feb 2017).

20. Lung FW, Chiang TL, Lin SJ, et al. Developing and refining the Taiwan Birth Cohort Study (TBCS): five years of experience. Res Dev Disabil 2011;32:2697-703.

21. Chan SSC, Cheung YTD, Leung DYP, et al. Secondhand smoke exposure and maternal action to protect children from secondhand smoke: pre- and post-smokefree legislation in Hong Kong. PLoS One 2014:9:e105781.

22. Blackburn C, Spencer N, Bonas S, et al. Effect of strategies to reduce exposure of infants to environmental tobacco smoke in the home: cross sectional survey. BMJ 2003;327:257.

23. Spencer N, Blackburn C, Bonas S, et al. Parent reported home smoking bans and toddler (18-30 month) smoke exposure: a crosssectional survey. Arch Dis Child 2005;90:670-4.

24. Wakefield M, Banham D, Martin J, et al. Restrictions on smoking at home and urinary cotinine levels among children with asthma. Am J Prev Med 2000;19:188-92.

25. Abdullah AS, Hua F, Khan $\mathrm{H}$, et al. Secondhand smoke exposure reduction intervention in Chinese households of young children: a randomized controlled trial. Acad Pediatr 2015;15:588-98.

26. Cheraghi M, Salvi S. Environmental tobacco smoke (ETS) and respiratory health in children. Eur $J$ Pediatr 2009;168:897-905.

27. Mao A, Bristow K, Robinson J. Caught in a dilemma: why do nonsmoking women in China support the smoking behaviors of men in their families? Health Educ Res 2013;28:153-64.

28. WHO. WHO recommendations for the prevention and management of tobacco use and second-hand smoke exposure in pregnancy. Geneva: WHO, 2013. http://apps.who.int/iris/bitstream/10665/94555/ 1/9789241506076_eng.pdf (accessed 24 Feb 2017).

29. Borland R, Mullins R, Trotter L, et al. Trends in environmental tobacco smoke restrictions in the home in Victoria, Australia. Tob Control 1999;8:266-71.

30. Borland $\mathrm{R}$, Yong $\mathrm{HH}$, Cummings $\mathrm{KM}$, et al. Determinants and consequences of smoke-free homes: findings from the International tobacco control (ITC) Four country survey. Tob Control 2006;15(suppl 3):iii42-50.

31. Cheng KW, Glantz SA, Lightwood JM. Association between smokefree laws and voluntary smokefree-home rules. Am J Prev Med 2011;41:566-72.

32. Fong GT, Cummings KM, Borland R, et al. The conceptual framework of the International tobacco control (ITC) Policy evaluation project. Tob Control 2006;15(Suppl 3):iii3-11.

33. Jacobs BS, Moss HA. Birth order and sex of sibling as determinants of mother-infant interaction. Child Dev 1976;47:315-22.

34. van ljzendoorn MH, Moran G, Belsky J, et al. The similarity of siblings' attachments to their mother. Child Dev 2000;71:1086-98. 
35. Hallers-Haalboom ET, Mesman J, Groeneveld MG, et al. Mothers, fathers, sons and daughters: parental sensitivity in families with two children. J Fam Psychol 2014;28:138-47.

36. Lai MC, Chou FS, Yang YJ, et al. Tobacco use and environmental smoke exposure among taiwanese pregnant smokers and recent quitters: risk perception, attitude, and avoidance behavior. Int $J$ Environ Res Public Health 2013;10:4104-16.
37. Lee AH. A pilot intervention for pregnant women in Sichuan, China on passive smoking. Patient Educ Couns 2008;71:396-401.

38. Zhang L, Hsia J, Tu X, et al. Exposure to secondhand tobacco smoke and interventions among pregnant women in China: a systematic review. Prev Chronic Dis 2015;12:E35.

39. Max W, Sung HY, Shi Y. Who is exposed to secondhand smoke? Self-reported and serum cotinine measured exposure in the U.S. 1999-2006. Int J Environ Res Public Health 2009;6:1633-48. 